\title{
The Good, the Bad and the Future: A SWOT Analysis of the Ecosystem Approach to Governance in the Baltic Sea Region
}

\author{
Savitri Jetoo * and Varvara Lahtinen
}

Citation: Jetoo, S.; Lahtinen, V. The Good, the Bad and the Future: A SWOT Analysis of the Ecosystem Approach to Governance in the Baltic Sea Region. Sustainability 2021, 13, 10539. https://doi.org/10.3390/ su131910539

Academic Editors: Baojie He, Ayyoob Sharifi, Chi Feng and Jun Yang

Received: 22 August 2021

Accepted: 18 September 2021

Published: 23 September 2021

Publisher's Note: MDPI stays neutral with regard to jurisdictional claims in published maps and institutional affiliations.

Copyright: (c) 2021 by the authors. Licensee MDPI, Basel, Switzerland. This article is an open access article distributed under the terms and conditions of the Creative Commons Attribution (CC BY) license (https:/ / creativecommons.org/licenses/by/ $4.0 /)$.
Faculty of Social Sciences, Business and Economics, Åbo Akademi University, Tuomiokirkontori 3, 20500 Turku, Finland; varvara.lahtinen@abo.fi

* Correspondence: savitri.jetoo@abo.fi

\begin{abstract}
The ecosystem approach has been used extensively as a guiding principle in water policies of the Baltic Sea Region since the 1970s. In addition to its operationalization as a management framework in this region, it also has expansive theoretical underpinnings. However, despite extensive literature on this approach, there has not yet been any systematic assessment of the internal and external factors that influence its implementation. This kind of assessment could form the basis for improved thinking around the concept and better implementation actions. As such, this article presents a Strengths, Weaknesses, Opportunities and Threats (SWOT) analysis of the ecosystem approach in the Baltic Sea Region by using content analysis on Baltic Sea documents. This study found that key strengths of the principle are its interdisciplinary focus and its acceptance as a framework for conservation, whilst resource intensiveness and its operational complexity are key weaknesses. The SWOT analysis revealed that a key opportunity in the external environment is the ease of alignment with other policies whilst the key external threat is the difficulty integrating disciplines. This study showed that with a streamlined allocation of resources, more stakeholder engagement through capacity building and political leadership, the ecosystem approach could facilitate interdisciplinary knowledge pooling to achieve a good ecological status of the Baltic Sea.
\end{abstract}

Keywords: ecosystem approach; Baltic Sea; SWOT analysis; implementation; water policy; water governance; barriers

\section{Introduction}

Humans constantly increase the stressors against the global marine ecosystems that, together with climate change, lead to severe loss of biodiversity, habitats and resources. It has already become apparent from the middle of the 20th century that traditional management practices could not address the ever-increasing loss of biodiversity [1-3]. The Ecosystem Approach (EA) is a concept that arose by the end of the 1980s, initially endorsed for the management of terrestrial ecosystems [1,2] to counteract the increasing loss of biodiversity. It emphasized the integration of information into management practices, the involvement of stakeholders in the decision-making process and the consideration of environmental relationships in different spatial, organizational and biological scales [2].

The term Ecosystem Management, conceptually similar to the ecosystem approach, was used to signify an ecosystem approach to resource management at the end of the 1980s [2]. Another similar concept, ecosystem-based management, emerged in the 1950s for managing terrestrial ecosystems [3-5]. The usage of many different terms (e.g., ecosystem approach, ecosystem-based management, ecosystem management, integrated management, etc.) in reference to similar concepts created confusion among scientists and practitioners [6,7]. Many researchers use ecosystem (-based) management and ecosystem approach interchangeably $[5,6,8]$. It is argued that there is a difference between the ecosystem approach and ecosystem management with the first being a vision and simultaneously a working plan for its realization, while the second is judged in human terms and may be altered [9]. 
The internationalization of the ecosystem approach occurred through the Convention of Biological Diversity (CBD), which adopted it as the framework for the implementation of its objectives [10]. According to the COP V/6 of the CBD, the ecosystem approach is "a strategy for the integrated management of land, water and living resources and promotes conservation and sustainable use in an equitable way" [11]. Furthermore, the CBD provided a list of 12 interlinked principles (Malawi principles) that characterize the ecosystem approach, and five points were proposed for guiding the operationalization of EA [11].

Regional Sea Conventions such as the Commission of the Convention on the Protection of the Marine Environment of the North-East Atlantic (OSPAR) and the Helsinki Commission (HELCOM) adapted the definition to the needs of their regional marine ecosystems. They jointly adopted "a vision of an ecosystem approach to managing human activities impacting on the marine environment (an "ecosystem approach") in their maritime areas" $[6,12]$. They defined the ecosystem approach as "the comprehensive integrated management of human activities based on the best available scientific knowledge about the ecosystem and its dynamics, in order to identify and take action on influences which are critical to the health of marine ecosystems, thereby achieving sustainable use of ecosystem goods and services and maintenance of ecosystem integrity" [12]. In 2007, HELCOM adopted the ecosystem approach in its Baltic Sea Action Plan (BSAP) [13] as it was defined in the first joint ministerial meeting of the Helsinki and OSPAR Commissions in 2003, and it calls for its implementation in the management of the Baltic Sea Region.

EA was also adopted by European Union (EU) policy documents. The Water Framework Directive (WFD) of 2000 did not explicitly mention the ecosystem approach but calls for the administrative reorganization of the water institutions to the appropriate scales according to the ecological borders [14]. The Marine Strategy Framework Directive (MSFD), adopted in 2008, explicitly refers to the application of the ecosystem-based approach to the management of human activities in the marine strategies of EU members for attaining good environmental status in the European marine regions and sub-regions [15]. However, the MSFD does not provide a definition for the ecosystem-based approach. The same term is also to be found in the EU Maritime Spatial Planning Directive (MSPD) of 2014, where the ecosystem-based approach will "contribute in the sustainable development and growth of the maritime and coastal economies and the sustainable use of marine and coastal resources" [16]. Furthermore, it identifies the maritime spatial planning as a tool for the application of the ecosystem-based approach in attaining good environmental status [16].

The ecosystem approach has been studied extensively globally but also within the Baltic Sea Region, which is this research's focus. One line of research focuses on the ecosystem approach to fisheries (EAF) or ecosystem-based fisheries management (EBFM) [17-21] that is not a fully cross-sectoral ecosystem approach but instead applies ecosystem-based policies within an individual sector [5]. Another line of research discusses appropriate ecosystem indicators to be developed for the implementation of ecosystem-based management [22-25]. A large part of the literature discusses frameworks as well as guidelines and the sequence of steps for the implementation of the ecosystem approach/management [5,26-28].

Against this backdrop of extensive literature discussing different aspects of EA, there has not yet been any systematic assessment of the internal and external factors that influence EA implementation in the Baltic Sea Region. This article intends to fill this gap by presenting a Strengths, Weaknesses, Opportunities and Threats (SWOT) analysis of the ecosystem approach in the Baltic Sea Region. The analytical framework itself guides the research questions of this study: what are the internal strengths and weakness of the ecosystem approach and what are the external opportunities and threats for the ecosystem approach in the Baltic Sea Region?

The purpose of this article is to provide a clear view of the key features that can promote or hinder the implementation of EA in the Baltic Sea Region and the achievement of good environmental status but also to inform the ongoing policy processes such as the updating of HELCOM's Baltic Sea Action Plan. 


\section{Materials and Methods}

This is a qualitative research process as illustrated in Figure 1. The SWOT and content analysis and further details of the research method are elaborated in the following sections.

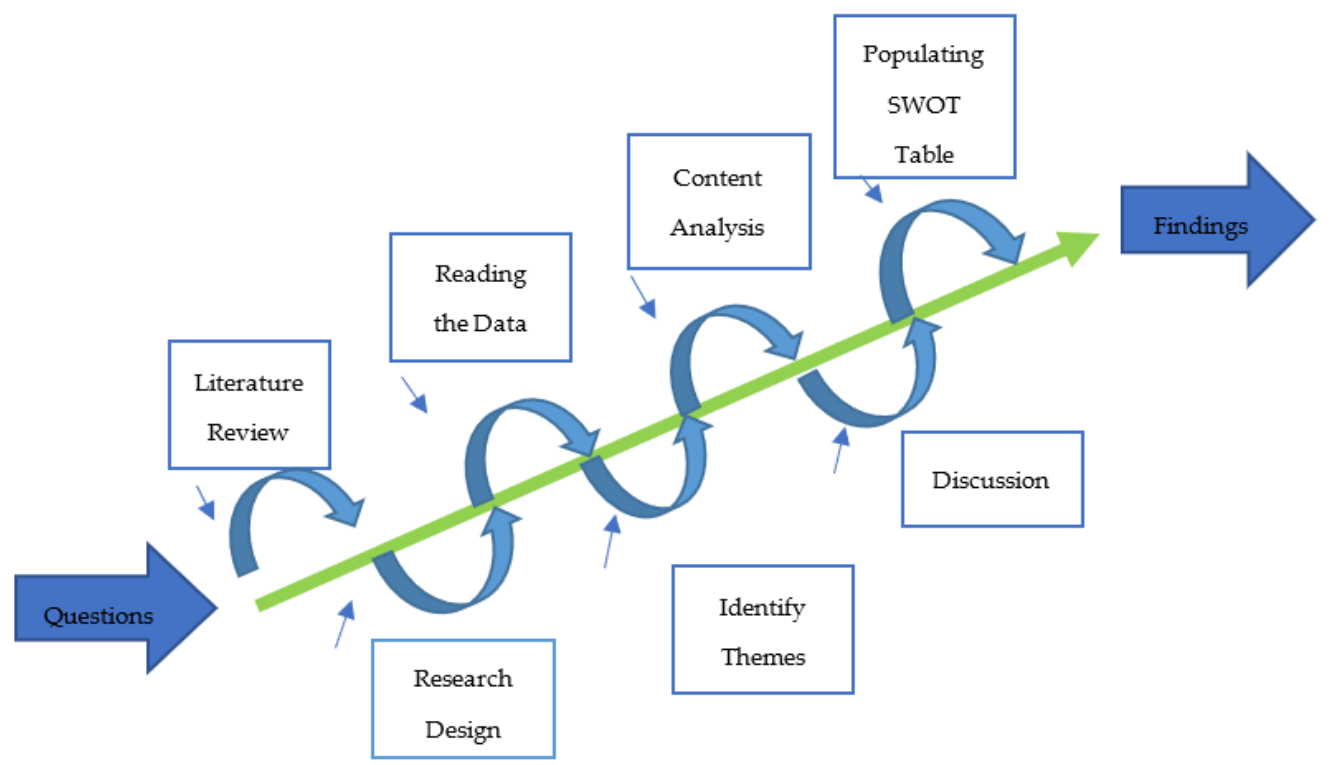

Figure 1. The research process.

\subsection{The SWOT Analysis}

The term SWOT derives from business literature and refers to Strengths, Weaknesses, Opportunities and Threats (SWOT) analysis. It is used as an assessment tool for strategic planning to position organizations to achieve their stated goals. The SWOT analysis is an effective tool for taking reconnaissance of the organization's resources and capabilities, its deficiencies, market opportunities and threats to its future [29]. The SWOT analysis views the performance of a given organization with respect to its goals and varies with the internal characteristics of that organization and the broader external context in which that organization must operate [30]. Strengths are internal characteristics that position the organization favorably towards the achievement of its goals, whereas weaknesses are internal factors that can detract from goal realization. Conversely, opportunities and threats are factors in the external environment that can facilitate or thwart the achievement of goals, respectively. These factors can include political, economic, social, technological, legal and environmental factors.

The SWOT analysis is a useful framework for analysis of the use of the ecosystem approach in the Baltic Sea Region as its value stems from the way the features of the concept interact in the external and internal environments to achieve its success. Its usefulness also arises from its ability to be used in the identification of barriers to success and the subsequent implementation of long-term strategies to achieve its objectives [31]. When applied to the ecosystem approach, the SWOT analysis can be applied to the features of the concept of the ecosystem approach that allow for the realization of its goals [32], to:

$>$ Consider the ecosystem as an integrated whole;

$>$ Use sustainability and people as the heart of achieving good environmental status; and

$>$ Value the services we obtain from nature.

In this context, strengths can be seen as the features of the ecosystem approach that allow for the achievement of the above stated goals, whilst weaknesses are characteristics of the approach that compromise the realization of these goals. As such, strengths and weaknesses are internal attributes of the ecosystem approach itself whilst opportunities and threats are external features that retard the realization of the above goals. In this case, external features are examined with respect to the Baltic Sea environment and the 
achievement of the good ecological status of the Baltic Sea. More specifically, the political, economic, sociological, technological, legal and environmental (later the PESTLE framework) factors within the implementation framework of the ecosystem approach in the context of the Baltic Sea Action Plan are considered. This is illustrated in Figure 2, with research questions included.

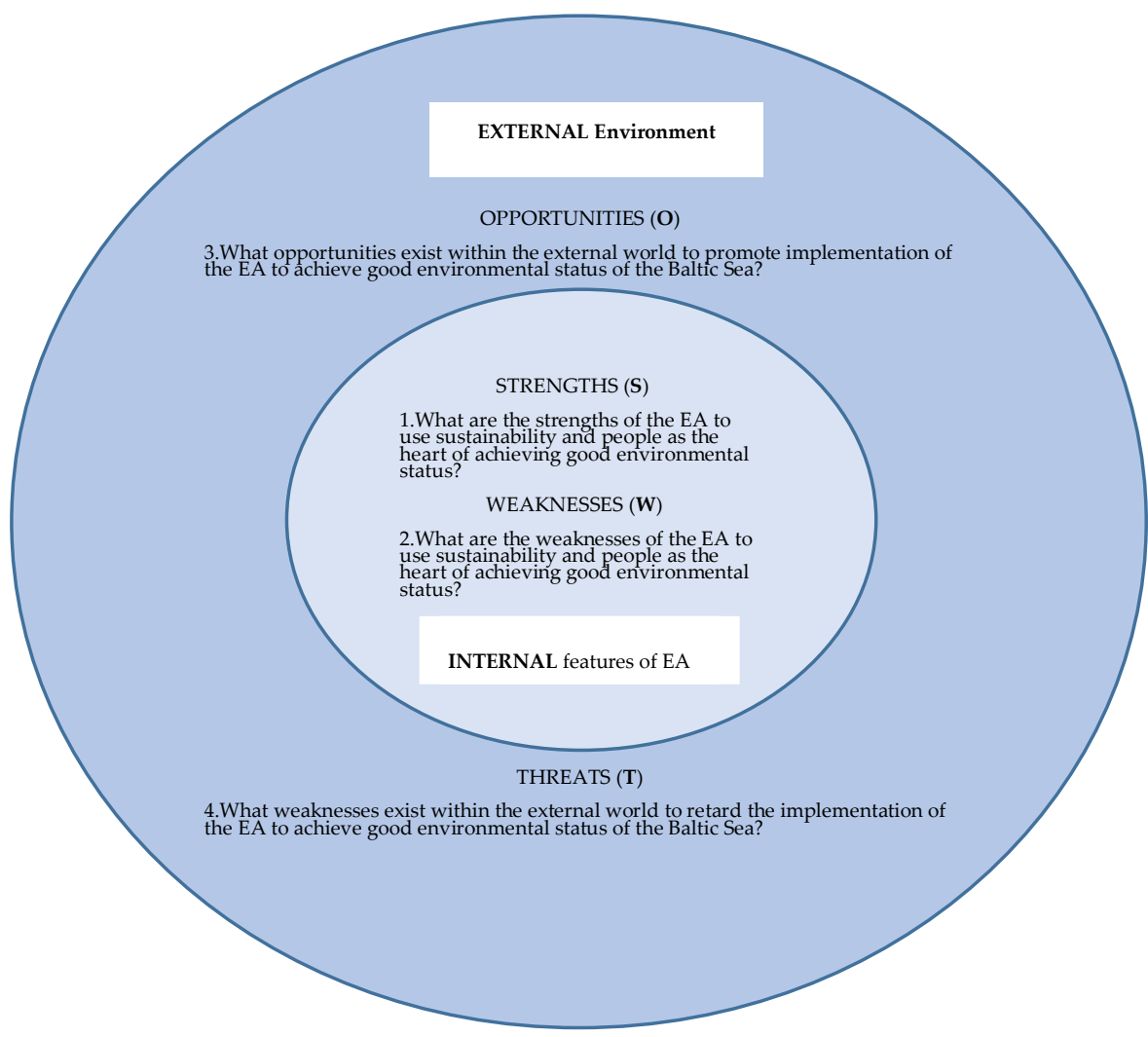

Figure 2. Research questions showing the internal and external SWOT environments.

\subsection{The Content Analysis}

The qualitative content analysis interprets the text's data content subjectively by using the systematic classification method of coding in the identification of patterns or themes [33]. It has an interpretive character that enables discussion on the points and themes that are essential to the study's research goal [34]. As a qualitative method, it has many advantages such as flexibility and applicability in a plethora of text types, being rather "safe" [35] and having "less rules to follow" by not being strictly linked to any specific science [36]. The disadvantages, on the other hand, are the inability to study other types of communication (e.g., body language, etc.) but the recorded communication-text, the potential loss of useful data due to restricted access or altogether missed data, its complexity and the fact that it is labor intensive and time consuming [35].

Qualitative content analysis was deemed the most appropriate method to be used in this research for a number of reasons. Firstly, due to the data used being existing documents and communications; secondly, due to their relatively limited numbers that renders their study attainable through qualitative content analysis and thirdly, due to qualitative content analysis being the most appropriate research method in answering the posed research questions.

The documents studied in this research were mainly the minutes from the meetings of the Group for the Implementation of the Ecosystem Approach (GEAR) [37]. GEAR is one of HELCOM's working groups, established in 2012 for coordinating the actions in implementing both the Baltic Sea Action Plan (BSAP) and the Marine Strategy Framework Directive (for the Contracting Parties also EU Member States). It also has oversight of 
pertinent global processes with the overarching goal being the implementation of EA and the achievement of good environmental status in the marine waters of the Baltic Sea [38]. By August 2021, the GEAR Group had 24 meetings. All 24 GEAR minutes and accompanying documents were studied but four of these minutes-documents were chosen specifically for coding analysis. These were the minutes of the GEAR 1 meeting (2012) [39], GEAR 13 (2016) [37], GEAR 18 (2018) [37] and GEAR 24 (2021) [37]. The GEAR 1 [39] and 24 [37] minutes were chosen to observe the changes the Group has undergone within the 9 years of operating. The GEAR 13 of 2016 [37] was chosen as the year when the EU Member States (also Contracting Parties) had to establish and implement Programmes of Measures (PoMs) in order to achieve Good Environmental Status (GES), set in Article 13 of MSFD (MSFD 2008); it was therefore interesting to observe how this mandate was met through the GEAR meeting. Finally, the GEAR 18 of 2018 [37] was chosen as the year of the beginning of the second cycle of MSFD implementation and therefore interesting to note how this process was reflected in the GEAR meeting.

The coding process began after having collected the documents. It is acknowledged that a successful qualitative analysis is the outcome of a well-thought out and well-executed coding process [33]. Therefore, the focus was kept on the research questions in order to avoid too broad or too narrow coding that would not answer them. The coding process did not aim at generating any theory, and therefore a deductive use of existing theoretical framework took place. The theoretical/conceptual framework utilized in this study was the 12 Malawi Principles of EA of the CBD [32]. After studying and discussing the Malawi Principles, some of the principles were somewhat overlapping and therefore condensed into themes that were relevant to the primary content of the principles and relevant to the Baltic Sea Region. The themes that emerged are as follows, with principle number in brackets: stakeholder participation (1), governance scale $(2,7,8)$, institutional arrangements $(3,6,9,10)$, economic considerations $(4,5)$ and science-policy interface $(11,12)$.

For the coding process, an excel spreadsheet was utilized for each GEAR minutes separately, where paragraphs from the minutes were inserted with their assigned theme as a code. Additionally, a column "remarks" was inserted where each minutes' paragraph was classified as internal strength or weakness, or as external threat or opportunity along with the justification for the classification. Many topics discussed in the minutes touched upon more than one theme and therefore assigned more than one code accordingly.

\section{Results}

This section presents the results of the SWOT analysis, focusing on each part of the SWOT analysis in turn.

\subsection{Strengths}

One of the key strengths of the ecosystem approach that was evident in all the themes and came across in the document analysis is the integrated approach in practice. This was evident in the meeting minutes, for example, in the Gear $24 \mathrm{~min}$, paragraphs 5.51-5.56, which noted the "plans for assessments for marine litter, integrated eutrophication assessment tool, underwater noise, integrated hazardous substances assessment tool" [37]. These paragraphs describe the latest developments on the topic of the assessments for marine litter, underwater noise, eutrophication, etc. HELCOM has developed the necessary tools for assessing all these stressors, and their efficient utilization can lead to accurate assessments that can facilitate the implementation of EA in management. It exemplifies an internal strength of the approach, which causes seemingly disparate areas to connect with each other in pursuit of one common overarching goal of good environmental status.

Another strength of the approach is its simplicity in communicating the necessity of humans to protect their environment, in this case, the good ecological status of the Baltic Sea. One theme throughout the GEAR meeting portal is that there is consensus that the ecosystem approach to management is the accepted guiding framework for the achievement of good ecological status of the Baltic Sea. The meeting minutes [37] demonstrate 
that there is agreement that everyone understands the guiding principles of the ecosystem approach and that humans are an integral part of ecosystems.

Stakeholder participation is one of the key features of EA and one of its internal strengths. The practice of stakeholder participation can be traced during different processes described in the GEAR minutes. The adequacy of participation or the breadth of stakeholders of course can be argued but nonetheless it is present in different occasions. For example, in GEAR $13 \mathrm{~min}$, the paragraphs from 4.14 to 4.17 discuss the national consultation process regarding the first results of HOLAS II. The comments that would occur from this consultation will feed the HOLAS II updating. Additionally, it was discussed the "option to have a regional consultation on the HOLAS II report ... oriented in particular towards an international audience in the Baltic Sea Region ... " [37]. A few more examples of stakeholder participation can be found in the minutes of GEAR 24, in paragraph 5.35, "a project meeting ... to enable interested experts and CPs to contribute more concretely to the development of driver indicators ..." " and in paragraph 6.2, "outcome of the HELCOM Stakeholder Conference in 2021 ... " [37]. Finally, already from its first meeting, GEAR discussed "how in principle the projects (steered by GEAR) should be carried out ... good involvement of national experts in the projects and project preparation ... better results than purely scientific ... of mainly external scientific institutions" [39].

Another internal strength of EA is the constant generation and updating of scientific data and indicators for better monitoring and assessing of different components of marine ecosystem. For example, the GEAR $24 \mathrm{~min}$ in paragraphs 5.17 to 5.23 discuss the establishment of a list of commercial species for the HELCOM area and (5.21) the "possible need to include species such as perch ... commercially important in some areas of the Baltic but for which data is not reported under the CFP." [37]. Furthermore, in 5.22, it was "agreed that all commercially exploited species ... should be included on the list ... only those species for which landings data is available can be included in the assessments ... collect initial information on the availability of landings data for regionally important commercial species for which data is not reported under the CFP." [37]. Though no scientific breakthrough is communicated through this example, the constant effort to improve the existing indicators for better monitoring is however evident.

One strength closely related to the constant generation of data and stakeholder participation is adaptation; an inherent feature of EA. Change is inevitable and is it recognized by EA, which encourages for the right adjustments and adaptations to it. This is exemplified in the minutes of GEAR 24, paragraph 6.6: the "current set up of the HELCOM Roadmap on EA is no longer optimal and that as part of updating the Roadmap in 2022 ... an approach more along the line of a meta-analysis would be more appropriate ... " [37]. The Group recognized the need for improvement and adjustments to fit the input from feedback loops for facilitating further EA implementation.

\subsection{Weaknesses}

The scientific and interdisciplinary basis of the ecosystem approach requires comprehensive monitoring data which may be difficult to implement due to resources limitations. This incomplete scientific information was a theme in the meeting minutes of the GEAR group. For example, in the first meeting minutes [39], Section 4.4 states that "new approaches for eutrophication targets ... the report should be considered as input from science to the HELCOM work ... acknowledging the views of Germany and Poland that it has its deficiencies in terms of data use ... HELCOM work continues to be based on science and its technical work should follow the best available science" [39]. This statement illustrates that there is incomplete data which hampers the achievement of eutrophication targets, as now HELCOM is forced to use the incomplete information, or best available science. Another inherent weakness is the inconsistency in the application of EA, due to the diverse interpretation of what it means and how it lends itself to the local context. For example, the Gear 1 meeting minutes demonstrate in Sections 4.2 and 4.3: "Poland ... requested information on sampling stations ... Poland to observe that only data from 
the 1980s and 1990s had been used ... most useful for the project to have data also from the end of the 1990s and 2000s ... proposals by the project for further sub-regionalized targets" [39]. These comments were made by delegates considering the final report of the HELCOM Approaches and methods for eutrophication target setting in the Baltic Sea Region (TARGREV) project [39]. Since Poland discharges one of the largest nutrient loads in the Baltic Sea Region, meeting participants were pointing out for the need for a more comprehensive data set to be able to set sub-regional targets.

An additional weakness of EA is the vastness of the marine ecosystem itself as well as a number of factors that cannot be monitored easily or issues of national jurisdictions or natural phenomena and climate change that cannot be fully predicted or controlled. This aspect is reflected in the minutes of GEAR 13 in paragraph 3.13 where "took note of the information on the national plans to use exceptions under MSFD Article 14 .. " [37] and it continues in presenting the exceptions used by the different Member States-Contracting Parties (CPs). Article 14 of MSFD [15] in essence gives the opportunity to the Member States (MS) to determine areas within their national marine waters that cannot meet the environmental targets or the GES within the time schedule due to a number of listed reasons. Those reasons include natural causes, unforeseeable circumstances that prevent MS to fulfill their obligation, natural conditions that hinder the prompt improvement of marine waters' status, etc.

\subsection{Opportunities}

One of the big opportunities of EA was recognized in the very first GEAR meeting minutes, which is the potential for alignment with existing policies and strategies and finding collaborative synergies with other countries and agencies. For example, the GEAR 1 meeting, Section 2.3 recognizes "The importance of starting early on with the regional coordination ... also cooperate with other organizations such as OSPAR and Black Sea Commission" [39]. This was further reiterated in Section 2.4, which went on to say that members "supported the alignment of the delivery of the relevant HELCOM products with timetables under other international frameworks" [39]. This theme continued forward in the GEAR 24 meeting minutes, where Section 6.7 looks into "use GEAR as a platform to share national experiences on implementing ecosystem based management (EBM), in the long term develop joint guidance on EBM, consider how to strengthen interactions with other sectors" [37].

These synergies can have further benefits apart from sharing knowledge, scientific data and expertise. These benefits can be the saving of resources, both in terms of funding and working force, avoiding duplication of work and unnecessary workload. This is clearly stated in GEAR 18 min, paragraph 3.7: "global fora are good channels to present ... high quality and best practices developed in the Baltic Sea Region ... the well-structured assessments ... from EU and RSC (Regional Sea Convention) work should be exported ... to avoid duplication of work ... " [37].

Another opportunity that surfaced in the GEAR 24 meeting minutes is the possibility to combine the potential for the alignment of policies with funding support. For example, Section 5.64 notes that "Sweden is looking into the possibility of providing additional resources to support the work under HOLAS III" [37] and 5.69 "Finland and Sweden investigate potential funding opportunities to support closer participation by Russia" [37]. The EU also provides funding support in the operationalization of projects that promote the implementation of MSFD and EA such as the BALSAM project, which provided recommendations for marine monitoring in the Baltic Sea. Such reference is found in GEAR 6 paragraph 3.26: "EC that is providing the main source of funding for BALSAM, that project goals and deliverables could in discussion with the EC be adjusted in order to make best use of resources" [40]. More supportive actions, even if their nature is not specified, we find in GEAR 13, paragraph 4.1, where Germany will continue supporting "activities that were not possible to finalize within the timeframe of the project (EUTRO-OPER) e.g., development of GES boundaries for new pre-core indicators ... " [37]. 
An additional opportunity in the implementation of EA in the Baltic Sea Region is performing both national and regional assessments for better management and implementation of EA. Such a statement is found in GEAR 24, paragraph 3.7: "regional and national assessment results ... valuable information even if these differ, with regional assessment ... a transboundary overview ... national level assessments enables results to be used for direct management needs which often take place at a local scale" [37].

Finally, the active participation of observers in GEAR meetings but also in actions taking place within HELCOM can be considered as an external opportunity in EA implementation in the Baltic Sea Region. Such an example is to be found in GEAR 18, paragraph 4.19: "the need to include those observers which have been taking part in the HOLAS II work" [37].

\subsection{Threats}

The top threats to the implementation of EA in the Baltic Sea Region relate to the themes already discussed. For example, inadequate funding is a possible threat to the third HELCOM Holistic assessments of the Baltic Sea environment (HOLAS III). This was captured in the GEAR 24 meeting minutes, Section 5.63: "resources allocated for HOLAS III ... further consideration on resources needs of the planned work ... very important that there are dedicated resources for drafting the HOLAS III texts in a coherent and readable manner" [37]. Planning for the funding is very important and it must be secured before the planned work began. Amidst the lack of resources, wasting them is an additional threat for EA implementation. Such a fear was discussed in GEAR 24 paragraph, 3.24: "careful consideration ... the added value of the resources required for the pre-filling ... to what degree countries will utilize this information" where a careful planning is required to avoid using resources to unutilized information" [37].

Another threat that was clearly articulated in the meeting minutes of GEAR 24 is the challenge of integrating the different disciplines. For example, Appendix 3 of the minutes speak of a future action by 2023 to "integrate economic and social analyses in HELCOM work ... for assessment of the linkages between the marine environment and human wellbeing, including carrying out regionally coordinated economic and social analysis of the marine environment" [37]. This difficulty of coordinating and integrating different approaches was tabled at the minutes of the GEAR meeting nine years earlier in 2012, when the GEAR 1st meeting minutes Section 3.15 stated that "the different approaches, lack of sufficient coordination and harmonization ... will be no possibility to coordinate and harmonize the targets between the neighboring countries' sea areas during the first implementation round of the MSFD" [39]. This quotation also points to the threat of inadequate political leadership to ensure collaborative governance for the meeting of the goals of the ecosystem approach.

An additional threat is the differences in national agendas, which can have various origins (differences in political will, in prioritizations, in resources, in capabilities, in data etc.). These differences can be reflected in GEAR, a group where mutual agreement is required for decisions to be made. Such an example can be found in the minutes of GEAR 13 in paragraphs 3.3 to 3.8 where study reservations on the "Consolidated version of the Joint documentation of regional coordination of programmes of measures in the Baltic Sea area" [37] by Denmark and Germany are discussed. In paragraph 3.6 is stated "the strict approach by Germany ... expected a number of its comments and proposed amendments ... to be agreed by the other CPs as a prerequisite to Germany clarifying its study reservation ... harsh action ... effectively blocks constructive work of the group ... against the good practice of HELCOM work" [37]. These kind of incidents may not be frequent but they certainly can have a disruptive effect on the implementation of EA.

The lack of consistency in the delegates of the CPs' presence in the GEAR meeting can pose an external threat for EA in the Baltic Sea Region. This issue was raised in GEAR 14 min, paragraph 2.3: "only four Contracting Parties were represented ... stressed that a better representation of Contracting Parties is needed Group to steer the implementation 
of the HELCOM BSAP and to facilitate the regional coordination for the implementation of the EA and the MSFD" [37].

Finally, partly ineffective tools can be considered as an external threat. Such an example can be found in GEAR 24, paragraph 4.9: "the information on the updated HELCOM Explorer" and 4.11 "could be refined to be more easily accessible for the general public ... proposals for simplifying the language" [37]. HELCOM Explorer is a very important tool because it gives the general public the opportunity to be informed about the different joint and national actions in the Region for the implementation of EA and to be part of this process, which mainly takes place among experts. Therefore, it should cater to the needs of the public and the language simplification is a step towards that direction.

\section{Discussion}

\subsection{Results of the SWOT Analsyis and Strategies Going Forward}

The results of the SWOT analysis as conducted for the Baltic Sea Region are summarized in Table 1. The research questions that this study posed were: what are the internal strengths and weaknesses of ecosystem approach to use sustainability and people as the heart of achieving good environmental status, and what are the external opportunities and threats to promote or retard the implementation of EA in achieving these goals in the Baltic Sea Region? The Baltic Sea Action Plan (BSAP) is HELCOM's key tool for achieving good ecological status of the Baltic Sea by 2021, while EU MSFD established a framework for achieving or maintaining GES by 2020, both having EA as their guiding principle. However, none of these realized their goal because GES has not yet been achieved in the Baltic Sea Region. Nonetheless, progress towards EA implementation has been made under these frameworks in the Region, a fact that should be not overlooked and understated and that was evident in the minutes of the GEAR meetings examined in this study. However, as Table 1 shows, there are key threats such as the difficulty integrating disciplines, inadequate funding, lack of consistent stakeholder participation and lack of political will that potentially undermine the strengths of the approach.

Table 1. Summary of SWOT results.

\begin{tabular}{|c|c|c|}
\hline & The GOOD & The BAD \\
\hline INTERNAL to EA & $\begin{array}{l}\text { STRENGTHS } \\
\text {-Integrated approach } \\
\text {-Interdisciplinary approach } \\
\text {-Simplicity } \\
\text {-Accepted framework for conservation } \\
\text {-Stakeholder participation } \\
\text {-Generation of scientific data, update of } \\
\text { indicators and creation of new ones } \\
\text {-Adaptation } \\
\text {-Brining persons closer to the environment }\end{array}$ & $\begin{array}{l}\text { WEAKNESSES } \\
\text {-Requires comprehensive data } \\
\text {-Resource intensive } \\
\text {-Incomplete scientific information } \\
\text {-Complex and difficult to apply in practice } \\
\text {-Unpredictability in ecosystem processes, } \\
\text { natural causes and phenomena and } \\
\text { climate change. }\end{array}$ \\
\hline $\begin{array}{l}\text { EXTERNAL including the Baltic } \\
\text { Sea Region }\end{array}$ & $\begin{array}{l}\text { OPPORTUNITIES } \\
\text {-Widely accepted framework for Baltic } \\
\text { Sea protection } \\
\text {-Can be easily aligned with existing policies } \\
\text { and strategies such as the UN sustainable } \\
\text { development goals (SDGs). } \\
\text {-Funding from EU pools for MSFD } \\
\text {-Synergies in reporting and monitoring } \\
\text { saving funds and avoiding duplication } \\
\text { of workload } \\
\text {-Regional and national assessments } \\
\text {-Observers' participation } \\
\text {-Technological and scientific } \\
\text { resource availability }\end{array}$ & $\begin{array}{l}\text { THREATS } \\
\text {-Difficulty integrating different disciplines } \\
\text {-Inadequate funding } \\
\text {-Inadequate resources e.g. personnel } \\
\text {-Lack of political will } \\
\text {-Different national agendas signifying } \\
\text { different approaches } \\
\text {-Lack of consistent participation of delegates } \\
\text {-Wasting resources } \\
\text {-Tools that may not fulfill their } \\
\text { purpose completely } \\
\text {-Lack of institutional capacity in some Baltic } \\
\text { Sea countries }\end{array}$ \\
\hline
\end{tabular}


This study has found confirmation of the usefulness of the ecosystem approach as a framework towards the achievement of the good ecological status of the Baltic Sea. It has extended previous studies on the ecosystem approach as it has applied the SWOT framework and is using it in the discussion of strategies for taking the approach forward into the current update of the Baltic Sea Action plan for more effective implementation. The strategies that will be discussed below flow out of a systematic examination of the threats and weaknesses and the utilization of the strengths and opportunities to mitigate those impediments.

\subsection{The Future—Strategies Going Forward}

These results are now used to devise strategies for moving forward with EA in the Baltic Sea Region. The SWOT analysis is not only a simple framework used to highlight strengths, weaknesses, opportunities and threats, but its additional value can be found in combining these elements in the development of strategies toward goal achievement. There are many ways to link the strategies from a SWOT analysis, based on the internal and external factors. According to the literature [41,42], four strategies can be developed, as follows: SO (strengths-opportunities), ST (strengths-threats), WO (weakness-opportunities) and WT (weakness-threats). This can be combined in a SWOT matrix, as follows [43]:

- SO strategies: taking advantage of opportunities

- ST strategies: avoiding threats

- WO strategies: introducing new opportunities by reducing weakness

- WT strategies: avoiding threats by minimizing weakness

\subsubsection{SO Strategies}

SO strategies are those combinations that allow internal strengths of the ecosystem approach to utilize external opportunities in the Baltic Sea environment. This combination of internal strengths of the ecosystem approach with the external opportunities in the Baltic Sea Region and other areas of the world could help to mitigate threats in the environment. Blending the strengths of the ecosystem approach, being an inherently interdisciplinary one with the opportunity of it being a widely held and accepted framework for Baltic Sea protection, could help to mitigate the threat of the difficulty of integrating different disciplines. A strategy recommendation would be to hold facilitated events such as workshops or conferences that bring together different disciplines to discuss the ecosystem approach in the Baltic Sea Region. Such workshops and conferences would also help to raise awareness and create a common understanding of the approach.

Stakeholder participation is an inherent strength of EA that helps to determine the objectives of ecosystem-based management. The Baltic Sea Region presents the great opportunity of broad participation of stakeholders in the process of developing EA. These stakeholders can be national experts participating in GEAR, experts working on EA actions in national contexts or observers from different organizations such as foundations, NGOs, etc. An example of strategy recommendation would be that by highlighting the significance of stakeholder participation in the core of EA, participating experts in the Baltic Sea Region can promote action that would further cultivate and elevate the participatory culture, addressing especially the countries that have less experience of it in their political systems. Furthermore, observers could also promote their experience in participating in Baltic Sea Region actions and the positive impact and effect such participation can have in protecting the environment and the achievement of GES. They could use the websites of their organization as platforms to promote such experiences to gain visibility and raise awareness. This combination of strengths and opportunities can also be used to combat the threat of the loss of political will, as showcasing the framework in public events would help to garner political support.

One of the EA cornerstones is the production of data and scientific knowledge, which is an important strength of the principle. The production of scientific data in the Baltic Sea Region is voluminous as it is a high priority in the region. More tools are developed, and 
more data are collected. One strategy action could be for HELCOM to export the expertise of creating tools and frameworks that have been effectively utilized in the Baltic Sea Region not only to other regions in Europe but also at an international level. The poor ecological status of the Baltic Sea due to its pollution, adding to its natural vulnerability, has led to a high scientific expertise in the Region that is constantly looking for more effective tools and framework. Such expertise in the Baltic Sea Region should become visible, recognized and exported globally to harness financial resources.

The opportunity of technological advances in the region along with the inherent strength of the scientific focus of the approach could help to mitigate the threat of lack of institutional capacity in some Baltic Sea countries. Environmental forerunners such as Finland, Sweden and Denmark could help in training staff of the environmentally weaker countries such as the Baltic States through mobility staff exchanges.

\subsubsection{ST Strategies}

ST strategies use internal assets to help lessen the impact of external threats in the Baltic Sea and wider world. The integrated, interdisciplinary focus of the ecosystem approach could be combined with the threat of integrating disciplines, leading to a strategy of increasing collaborations among disciplines. It is noted that HELCOM has a natural sciences focus, so collaborations should be extended with the humanities and the social sciences to gather local knowledge to combat stressors such as climate change.

The internal strength of stakeholder participation could be coupled with the threat of the voluntary participation of national delegates in HELCOM processes. A strategy recommendation may be to detect the reasons behind the occasional lack of participation and trying to address those reasons if possible. For example, if delegates cannot be present to a certain venue due to lack of funds or excessive workload, then actions could be taken to find some funds or hold the meetings in a virtual manner, in a hybrid mode, in order for more delegates and observers to participate in the meetings.

Another possible combination may be the internal strength of data collection and knowledge production in conjunction with the threat of developed tools not completely fulfilling their purpose. The constant development of methods and tools for collecting information about the marine ecosystems in the Baltic Sea and their monitoring has been a very important component of EA implementation in the Region. A strategic recommendation would be a more careful design of tools and possibly their pilot use to determine their performance in their designated task before their release to broad use. The constant scientific research with a broadening interdisciplinary focus will lead to gains in knowledge on EA implementation. Therefore, it can inform the process of developing tools suited to purpose, in order to avoid wasting resources by creating impractical tools.

\subsubsection{WO Strategies}

WO strategies are those that use external opportunities in the Baltic Sea environment and wider world to mitigate the internal flaws of the ecosystem approach. One opportunity that recurs in HELCOM's meeting minutes is the alignment of the ecosystem approach with other frameworks such as the sustainable development goals (SDGs). This can be harnessed in overcoming the weakness of the approach in being complex and difficult to apply in practice. A strategy to do this will see experts of EA helping managers and non-specialists to understand the approach and to apply the tools of the approach. They can be part of project teams that help in the implementation of the approach on the ground in the Baltic Sea Region. This could result in greater understanding, uptake and local ownership of the ecosystem approach.

One important external opportunity in the Baltic Sea Region is conducting assessments at both a national and regional level for fulfilling the requirements of the MSFD, among other things, since eight out of the nine countries-CPs of HELCOM are also member states of the EU. This opportunity can be combined with the inherent weakness of EA, which is the incomplete scientific data for EA implementation. A strategic recommendation could 
call for intensifying the combination of the data collected at a national and regional level in the Region in order to fill in the gaps of scientific knowledge. Furthermore, national assessments can provide data for smaller geographical areas and be more specific. This information should be utilized in a manner that would enhance knowledge of more components of the marine ecosystems of the Baltic Sea and it would promote further the implementation of EA.

An often-reoccurring opportunity in the GEAR meetings is the synergies in processes such as reporting and monitoring that can lead to saving funds as well as less workload. It can be combined with the internal weakness of EA of being resource-intensive and requires many comprehensive data. There is already a broad network of collaboration between HELCOM and other organizations in the Baltic Sea Region and at an international level. A strategic action could be to enhance the existing collaboration and to assign tasks in a coordinated manner so as to share different monitoring and reporting processes and costs. The collaborations aimed at producing data in the Baltic Sea Region could be strengthened in order to produce solid scientific data to export for international assessments in ameliorating the weakness of increased resources and data requirements for EA implementation.

\subsubsection{WT Strategies}

WT is the double whammy strategy, as it consists of strategies aimed at lessening internal weaknesses and external threats at the same time. Lessening the negative effects of threats and weaknesses simultaneously can be confounding. The weakness of the approach being resource-intensive combined with the threat of inadequate funding could be addressed by utilizing funding pools available from the EU. As such, it would be pertinent to identify the funding gaps and their causes and to combine this with matching these gaps to the pools available.

The important internal weakness of EA, the incomplete scientific data information, and the external threat of inadequate resources, e.g., personnel, could be addressed together. A strategic recommendation would be to actively pursue more collaboration agreements with scientific institutes in the Region; for example, with universities that could assist in producing knowledge and at the same time would address the issue of lack of scientific personnel. Universities, having their own pools of funding, would not pose any additional financial burden to the process of EA implementation in the Region and they have the expertise and the experience to provide valuable assistance in accumulating additional scientific data for EA.

Another weakness, that of EA being complex and difficult to apply, may be approached together with the threat of different national agendas. It is very hard for one to address the threat of different national agendas adequately or to change the fact that EA is difficult to apply since at its very heart lies the marine ecosystem that is complex and unpredictable. However, one strategic action could be to increase the visibility of EA at the national level and especially to the broad public. Through events or workshops addressing different parts of the populations and different local groups, EA can be promoted and become less of a complex principle by actively educating the public, emphasizing their participation and support. The more visibility and recognition gains among the broad public, the more chances are for the official national attitudes to change towards it and be more actively involved in EA implementation if they have not been already.

\subsection{Malawi Principles in the Baltic Sea Region}

This section now considers how the implementation of the ecosystem approach in the Baltic Sea Region corresponds to the vision espoused in the Malawi principles (Table 2). This is based on the results from the SWOT analysis. Table 2 clearly illustrates that there are different degrees of implementation of the ecosystem approach in the Baltic Sea Region. There is management autonomy to choose actions and planning time frames, with management recognizing changes in line with the Malawi principles. However, there is still the sectoral approach, with silos operating, signaling the need for better collaboration 
and policy coherence at the local (e.g., municipalities), national (e.g., ministries), regional (EU level) and international levels. There is also not enough recognition and use of local knowledge. The local level is still not adequately represented in the decision-making process. One of the key areas for improvement is highlighted in principle 12, the need for better stakeholder engagement. Communication and capacity building of all stakeholders can lead to better implementation through an increased understanding of ecosystem interactions and hence the adoption of policies by stakeholders, leading to better science policy processes.

Table 2. Malawi principles in the Baltic Sea Region (Green-achieved; Red-not achieved; Grey-somewhat achieved).

Malawi Principle

Management objectives are a matter of societal choice.

Management should be decentralized to the lowest appropriate level.

Ecosystem managers should consider the effects of their activities on adjacent and other ecosystems.

Recognizing potential gains from management, there is a need to understand the ecosystem in an economic context, considering, e.g., mitigating market distortions, aligning incentives to promote sustainable use and internalizing costs and benefits.

A key feature of the ecosystem approach includes conservation of ecosystem structure and functioning.

Ecosystems must be managed within the limits to their functioning.

The ecosystem approach should be undertaken at the appropriate scale.

Recognizing the varying temporal scales and lag effects which characterize ecosystem processes, objectives for ecosystem management should be set for the long term.

Management must recognize that change is inevitable.

The ecosystem approach should seek the appropriate balance between conservation and use of biodiversity.

The ecosystem approach should consider all forms of relevant information, including scientific, indigenous and local knowledge, innovations and practices.

The ecosystem approach should involve all relevant sectors of society and scientific disciplines.
Implementation in the Baltic Sea Region

This is in full implementation in the Baltic Sea Region as HELCOM gives contracting parties freedom in deciding how measures are met. For example, GEAR 24 meeting minutes state that "The Meeting concluded that national reporting, irrespective of which approach is used, needs to capture the scale and methodology used for the assessment results used".

GEAR meetings were attended mainly by national-level representatives. As such, this objective is not yet achieved in the Baltic Sea Region.

There is some evidence of this, but there is need for strengthening collaboration between sectors. GEAR 24 meeting minutes note that "The Meeting took note of the list of activities and pressures to be used across the HELCOM Working Groups for linking the activities and pressures to the proposed BSAP actions". HELCOM's work on linking activities and pressures is evidence of this principle in progress.

There is now recognition in the Baltic Sea community of the need to include socio-economic assessments into current targets. The 2021 GEAR 24 meeting minutes had an entire Annex 3 dedicated to the integration of social and economic analysis into an update of the Baltic Sea Action Plan.

This is acknowledged in the BSAP guiding principles but not achieved in practice as the Baltic Sea ecosystem is under pressure from stressors such as eutrophication.

Due to the above, this principle is not met. The 'limit to functioning' is not fully understood for the Baltic Sea, as there is not sufficient data to determine what is the integrated limit to functioning (as opposed to the silo approach of, e.g., fisheries)

The holistic assessments compiled by HELCOM are done at different scales (such as the different bays of the Baltic Sea), so this is somewhat achieved. However, since there are not enough data, the appropriate scale is sometimes not achievable.

The time frames for Baltic Sea action are generally long term, as HELCOM sets, e.g., 14-year targets for the first BSAP. It is generally recognized that the ecosystem of the Baltic Sea takes a long time to recover after management actions are taken.

This is written into policy documents such as the BSAP, as it recognizes that monitoring should be continuous to cater for changes in the ecosystem.

This is not a principle achieved in practice in the Baltic Sea Region. Resources are used outside the limits of conservation in some areas, eg., in agriculturally-dependent economies

Whilst the Baltic Sea Region and HELCOM have been hailed as leaders in collecting and sharing information, there is still the need to incorporate local and indigenous knowledge into the decision-making process.

There is much room for improvement here. Whilst HELCOM allows observers in its meetings, they are not given decision-making powers. The practice of engaging the local public in environmental decision-making varies with each contracting party.

\section{Conclusions}

There is much literature on the ecosystem approach, but the novelty of this work is that it systematically studies the ecosystem approach using the strengths, weaknesses, opportunities and threats (SWOT) framework. This method not only highlights key aspects of the ecosystem approach but enables the development of strategies for further optimization of the implementation of the approach in the Baltic Sea Region and beyond. 
This research presents the findings from the Baltic Sea Region, one of the largest water catchment regions in the world and a part of the European Union. It has shown that the ecosystem approach to management is a means by which to capture the intricacies of the relationship between humans and the Sea (the environment). Findings reveal that one of the advantages of the ecosystem approach that Baltic Sea experts cherish is its simplicity in communicating the importance of Baltic Sea protection. However, the caveat is that the language of the ecosystem approach can be complex and unclear, hence it can serve as the link between research and practical implementation. This research has recommended that the implementation of the ecosystem approach is most effective when using existing tools and incorporating into prevailing policies. On a wider scale, the ecosystem approach is not only useful in management decision making but also as a means of conveying the complexities of the relationship between humans and the environment. Resource allocation backed by strong political leadership can strengthen interdisciplinary research so that the ecosystem approach can be better integrated with sustainability policies and practices.

This study has utilized the SWOT framework to highlight key aspects of the ecosystem approach that can be further developed for better implementation in the Baltic Sea Region and beyond. This research can be seen as the platform from which other dialogue and further research emerges as outlined below:

- This study utilized a document analysis of key documents to identify themes relevant to the ecosystem approach in the Baltic Sea Region. Further research can employ a survey of key stakeholders in the Baltic Sea Region at all levels in the multi-level governance framework.

- As an extension to the point above, it would be interesting to carry out a survey that considers key demographics such as different groups in society and ages, to see how the perception of the ecosystem approach varies generationally.

- Given the interdisciplinary nature of the ecosystem approach, it would be interesting to convene stakeholders from different disciplines in focus groups and conduct a SWOT analysis in a workshop-style environment. This can feed into the survey results above and help to overcome any potential compiler bias.

- Studies on the implementation of the ecosystem approach at various levels in the Baltic Sea Region and comparisons with other areas of the world would provide valuable empirical data on strategies for success and implementation deficits.

- Another key area of study that would help in taking the ecosystem approach forward would be the development of new indicators that reflect the interdisciplinary focus of the approach. For example, governance indicators and stakeholder engagement indicators are some that would provide useful information.

Author Contributions: This article was conceptualized by S.J. and V.L. and outline drafted by S.J. and V.L. Literature review, methods and results and discussion written by both S.J. and V.L. Coding and data analysis done by both V.L. and S.J. Both authors have read and agreed to the published version of the manuscript.

Funding: This research received academy of Finland SeaHer funding, grant number 315715. The authors also wish to acknowledge support from the 'Sea' profiling area of Åbo Akademi University.

Institutional Review Board Statement: Not applicable.

Informed Consent Statement: Not applicable.

Data Availability Statement: All data is stored centrally at Åbo Akademi University.

Conflicts of Interest: The authors declare no conflict of interest.

\section{References}

1. Grumbine, R.E. What is ecosystem management? Conserv. Biol. 1994, 8, 27-38. [CrossRef]

2. Szaro, R.C.; Sexton, W.T.; Malone, C.R. The emergence of ecosystem management as a tool for meeting people's needs and sustaining ecosystems. Landscape Urban Plan. 1998, 40, 1-7. [CrossRef] 
3. Kirkfeldt, T.A. Why choosing between ecosystem-based management, ecosystem-based approach and ecosystem approach makes a difference. Mar. Policy 2019, 106, 103541. [CrossRef]

4. Rodriguez, N.J.I. A comparative analysis of holistic marine management regimes and ecosystem approach in marine spatial planning in developed countries. Ocean Coast Manage. 2017, 137, 185-197. [CrossRef]

5. Agardy, T.; Davis, J.; Sherwood, K. Taking Steps toward Marine and Coastal Management—An Introductory Guide; Series: UNEP Regional Seas Reports and Studies No. 189; UNEP: Nairobi, Kenya, 2011; pp. 1-68.

6. Engler, C. Beyond rhetoric: Navigating the conceptual tangle towards effective implementation of the ecosystem approach to oceans management. Environ. Rev. 2015, 23, 288-320. [CrossRef]

7. Yaffee, S.L. Three Faces of Ecosystem Management. Conserv. Biol. 1999, 13, 713-725. [CrossRef]

8. Arkema, K.K.; Abramson, S.C.; Dewsbury, B.M. Marine ecosystem-based management: From characterization to implementation. Front. Ecol. Environ. 2006, 4, 525-532. [CrossRef]

9. Söderström, S.; Kern, K. The Ecosystem Approach to Management in Marine Environmental Governance: Institutional interplay in the Baltic Sea Region. Environ. Policy Gov. 2017, 27, 619-631. [CrossRef]

10. Conference of the Parties (Convention on Biological Diversity). Report on the Workshop on the Ecosystem Approach. In Proceedings of the item 13 of the provisional agenda of Fourth meeting, Bratislava, Slovakia, 4-15 May 1998.

11. Conferences of the Parties (Convention on Biological Diversity). Decision V/6 'Ecosystem Approach'. In Proceedings of the Fifth Ordinary Meeting of the Conference of the Parties to the Convention on Biological Diversity, Nairobi, Kenya, 15-26 May 2000.

12. Convention on the Protection of the Marine Environment of the Baltic Sea Area (Helsinki Convention) and OSPAR Convention for the Protection of the Marine Environment of the North-East Atlantic. In Proceedings of the First Joint Ministerial Meeting of the Helsinki and OSPAR Commissions (JMM). Statement towards an Ecosystem Approach to the Management of Human Activities, “Towards an Ecosystem Approach to the Management of Human Activities", Bremen, Germany, 25-26 June 2003; Available online: https://www.ospar.org/site/assets/files/1232/jmm_annex05_ecosystem_approach_statement.pdf (accessed on 2 July 2021).

13. HELCOM Baltic Sea Action Plan. In Proceedings of the HELCOM Ministerial Meeting, Krakow, Poland, 15 November 2007; Available online: http:/ / helcom.fi/baltic-sea-action-plan (accessed on 15 July 2021).

14. Hammer, M.; Balfors, B.; Mörtberg, U.; Petersson, M.; Quin, A. Governance of water resources in the phase of change: A case study of the implementation of the EU Water Framework Directive in Sweden. Ambio 2011, 40, 210-220. [CrossRef]

15. Directive 2008/56/EC of the European Parliament and of the Council of 17 June 2008 establishing a Framework for Community Action in the Field of Marine Environmental Policy (Marine Strategy Framework Directive). Off. J. Eur. Union 2008, $164,1-22$.

16. Directive 2014/89/EU of the European Parliament and of the Council of 23 July 2014 establishing a Framework for Maritime Spatial Planning. Off. J. Eur. Union 2014, 257, 1-11.

17. Doyen, L.; Thébaud, O.; Béné, C.; Martinet, V.; Gourguet, S.; Bertignac, M.; Fifas, S.; Blanchard, F. A stochastic viability approach to ecosystem-based fisheries management. Ecol. Econ. 2012, 75, 32-42. [CrossRef]

18. Garcia, S.M.; Rice, J.; Charles, A. Balanced harvesting in fisheries: A preliminary analysis of management implications. ICES J. Mar. Sci. 2016, 73, 1668-1678. [CrossRef]

19. Kolding, J.; Garcia, S.M.; Zhou, S.; Heino, M. Balanced harvest: Utopia, failure, or a functional strategy? ICES J. Mar. Sci. 2016, 73, 1616-1622. [CrossRef]

20. Cavanagh, R.D.; Hill, S.L.; Knowland, C.A.; Grant, S.M. Stakeholder perspectives on ecosystem-based management of the Antarctic krill fishery. Mar. Policy 2016, 68, 205-211. [CrossRef]

21. Coll, M.; Cury, P.; Azzurro, E.; Bariche, M.; Bayadas, G.; Bellido, J.M.; Chaboud, C.; Claudet, J.; El-Sayed, A.F.; Gascuel, D.; et al. Workshop Participants. The scientific strategy needed to promote a regional ecosystem-based approach to fisheries in the Mediterranean and Black seas. Rev. Fish Biol. Fisher. 2013, 23, 415-434. [CrossRef]

22. O'Boyle, R.; Sinclair, M.; Keizer, P.; Lee, K.; Ricard, D.; Yeats, P. Indicators for ecosystem-based management on the Scotian Shelf: Bridging the gap between theory and practice. ICES J. Mar. Sci. 2005, 62, 598-605. [CrossRef]

23. Rees, H.L.; Boyd, S.E.; Schratzberger, M.; Murray, L.A. Role of benthic indicators in regulating human activities at sea. Environ. Sci. Policy 2006, 9, 496-508. [CrossRef]

24. Rees, H.L.; Hyland, J.L.; Hylland, K.; Mercer Clarke, C.S.L.; Roff, J.C.; Ware, S. Environmental indicators: Utility in meeting regulatory needs. An overview. ICES J. Mar. Sci. 2008, 65, 1381-1386. [CrossRef]

25. Bayer, E.; Barnes, R.A.; Rees, H.L. The regulatory framework for marine dredging indicators and their operational efficiency within the UK: A possible model for other nations? ICES J. Mar. Sci. 2008, 65, 1402-1406. [CrossRef]

26. Curran, K.; Bundy, A.; Craig, M.; Hall, T.; Lawton, P.; Quigley, S. Recommendations for Science, Management, and an Ecosystem Approach in Fisheries and Oceans Canada, Maritimes Region. DFO Can. Sci. Advis. Sec. Res. 2012, Doc. 2012/061. Available online: http:/ / www.dfo-mpo.gc.ca/csas-sccs/Publications/ResDocs-DocRech/2012/2012_061-eng.html (accessed on 2 July 2021).

27. Stephenson, R.L.; Hobday, A.J.; Cvitanovic, C.; Alexander, K.A.; Begg, G.A.; Bustamante, R.H.; Dunstan, P.K.; Frusher, S.; Fudge, M.; Fulton, E.A.; et al. A practical framework for implementing and evaluating integrated management of marine activities. Ocean Coast. Manage. 2019, 177, 127-138. [CrossRef]

28. Leslie, H.; Sievanen, L.; Crawford, T.G.; Gruby, R.; Villanueva-Aznar, H.C.; Campbell, L.M. Learning from Ecosystem-Based Management in Practice. Coast. Manage. 2015, 43, 471-497. [CrossRef]

29. Gürel, E.; Tat, M. SWOT analysis: A theoretical review. J. Int. Soc. Res. 2017, 10, 994-1006. [CrossRef] 
30. Minsky, L.; Aron, D. Are You doing the SWOT Analysis Backwards? Harvard Business Review. 2021. Available online: https://hbr.org/2021/02/are-you-doing-the-swot-analysis-backwards (accessed on 6 October 2020).

31. Houben, G.; Lenie, K.; Vanhoof, K. A knowledge-based SWOT-analysis system as an instrument for strategic planning in small and medium sized enterprises. Decis. Support Syst. 1999, 26, 125-135. [CrossRef]

32. CBD. Secretariat of the Convention of Biological Diversity (CBD); The Ecosystem Approach CBD Guidelines; CBD: Montreal, QC, Canada, 2004.

33. Hsieh, H.-F.; Shannon, S.E. Three Approaches to Qualitative Content Analysis. Qual. Health Res. 2005, 15, 1277-1288. [CrossRef]

34. Williamson, K.; Given, L.M.; Scifleet, P. Qualitative data analysis. In Research Methods, Information, Systems and Contexts, 2nd ed.; Williamson, K., Johanson, G., Eds.; Elsevier Ltd.: Amsterdam, The Netherlands, 2018; pp. 453-476.

35. Maier, M.A. Content Analysis: Advantages and Disadvantages. In The SAGE Encyclopedia of Communication Research Methods; Allen, M., Ed.; SAGE Publications, Inc.: Newcastle upon Tyne, UK, 2017; pp. 240-242.

36. Bengtsson, M. How to plan and perform a qualitative study using content analysis. Nurs. Open. 2016, 2, 8-14. [CrossRef]

37. HELCOM Meeting Portal. Available online: https://portal.helcom.fi/Lists/MeetingInformation/GEAR\%20meetings.aspx (accessed on 5 July 2021).

38. HELCOM GEAR Group on the Implementation of Ecosystem Approach. Available online: https://helcom.fi/helcom-at-work/ groups/gear/ (accessed on 8 January 2021).

39. Minutes of the First Meeting of HELCOM Group for the Implementation of the Ecosystem Approach (HELCOM GEAR), Bonn Germany. 2012. Available online: https://portal.helcom.fi/Archive/Shared\%20Documents/GEAR\%201-2012_Minutes\%20 GEAR1.pdf\#search=\%22GEAR\%201\%22 (accessed on 20 July 2021).

40. Outcome of the Sixth Meeting of HELCOM Group for the Implementation of the Ecosystem Approach (HELCOM GEAR), Berlin, Germany. 2014. Available online: https:/ / portal.helcom.fi/Archive/archive2/GEAR\%206-2014_Outcome\%20of\%20GEAR\% 206-2014.pdf\#search=\%22GEAR\%206\%22 (accessed on 25 July 2021).

41. Bayram, B.C.; Ucvncv, T. A Case Study: Assessing the Current Situation of Forest Products Industry in Taşköprü through SWOT Analysis and Analytic Hierarchy Process. Kast. Univ. J. For. Faculty. 2016, 16, 510-514. [CrossRef]

42. David, F.R.; Creek, S.A.; David, F.R. What is the Key to Effective SWOT Analysis, Including AQCD Factors. SAM Adv. Manage. J. 2019, 84, 25.

43. Benzaghta, M.A.; Elwalda, A.; Mousa, M.M.; Erkan, I.; Rahman, M. SWOT analysis applications: An integrative literature review. J. Glob. Bus. Insights 2021, 6, 54-72. [CrossRef] 